\title{
Transient 3D CFD Simulation of a Stationary Vane, Oil Free, Rotary Compressor
}

\author{
Balázs Farkas ${ }^{1 *}$, Jenő Miklós Suda \\ 1 Department of Fluid Mechanics, Faculty of Mechanical Engineering, Budapest University of Technology and Economics, \\ H-1111 Budapest, Bertalan Lajos utca 4-6, Hungary \\ *Corresponding author, e-mail: farkas@ara.bme.hu
}

Received: 15 February 2019, Accepted: 04 July 2019, Published online: 23 August 2019

\begin{abstract}
The evaluation of a newly designed oil-free rotary compressor is presented based on transient 3D Computational Fluid Dynamics (CFD) simulations. The simulations are performed at low compression ratios and low pressure ratios and low rotational speeds. To place the results into context, the data presented in related literature was processed and summarized. The methods related to the CFD model of the newly designed compressor were developed, summarized and evaluated. The accessed CFD data are in good agreement with the results of the former rolling piston compressor related investigations. The oil free operation prevents the contamination of the working fluid from lubricant. Since the compressor is planned to work in open cycle within the sensitive environment of thermal heat sources contamination free operation has to be accomplished. However, oil-free operation also results in significantly lower performance based on the modelling results.
\end{abstract}

\section{Keywords}

stationary vane compressor, CFD, compressor performance, dynamic mesh

\section{Introduction}

Rolling piston compressors (RPC) or often referred more generally as stationary vane compressors are mainly applied in low capacity $(<2 \mathrm{~kW})$ household refrigerator, air-conditioning (AC) and heat pump units $[1,2]$. The widespread interest in the use of the RPCs in small AC's from the early 1970's is the consequence of their high efficiency, compact size, simple construction and smoother and more quiet operation compared to the reciprocating compressors [3-5]. Because of the advantageous attributes, the RPC's were considered to be suitable for various other purposes beside the utilization in residential climatization applications. Common structure of a RPC typical in AC units is presented in Fig. 1.

The basic pressurization process within a stationary vane compressor is illustrated in Fig. 2.

As the compressor rotates clockwise, the volume of the compression chamber decreases. The subsequent pressurization continues until the pressure of the working fluid $\left(p_{c}\right)$ reaches the discharge pressure $\left(p_{d}\right)$. Ideally at this point the discharge valve, which prevents the backflow from the discharge port opens and the pressurized working fluid is discharged from the compression chamber. The suction takes place simultaneously with the compression.

The construction of the stationary vane rotary machines was first introduced by Bourne [6] as early as 1836 in the wave of the industrial revolution. The presented steam turbine applies the same principle but implement the reversed cycle compared to the RPC's.

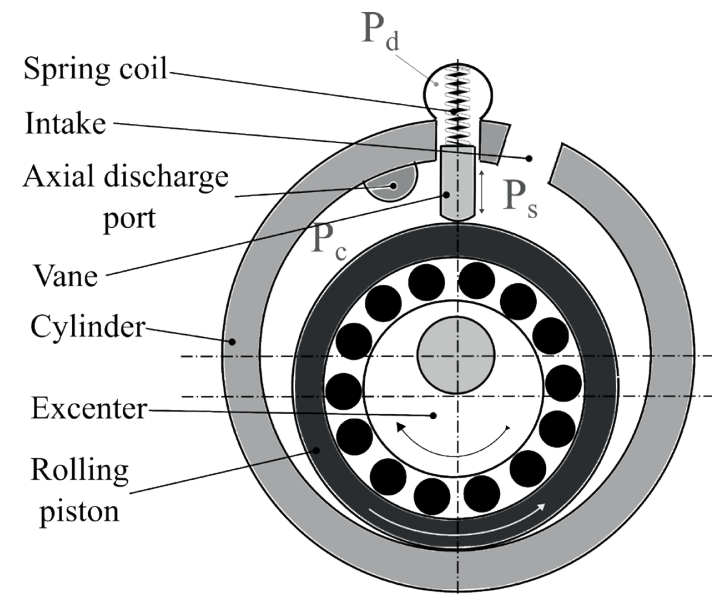

Fig. 1 Schematic of a common rolling piston compressor for AC units 


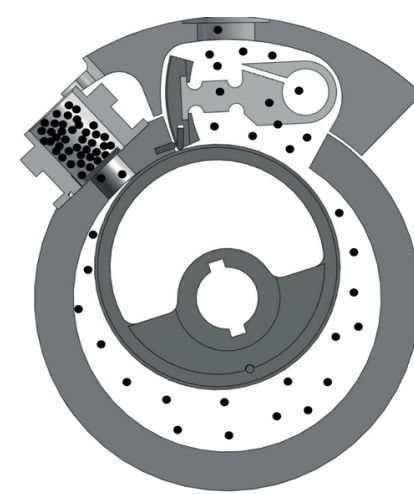

(a)

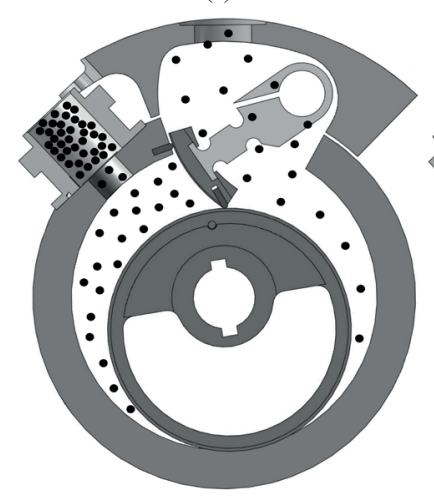

(c)

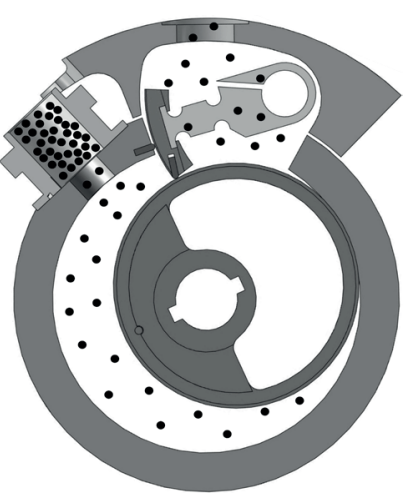

(b)

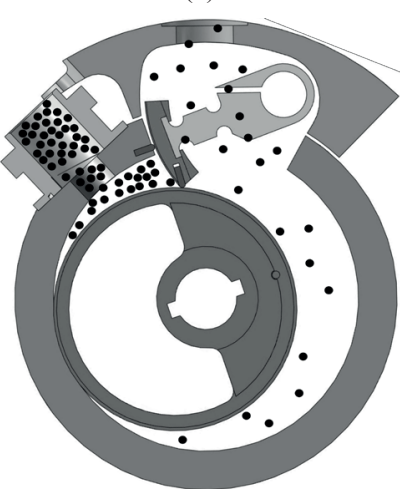

(d)
Fig. 2 Illustration of stationary vane compressor operation principle: (a) $\Theta=0^{\circ}$, (b) $\Theta=90^{\circ}$, (c) $\Theta=180^{\circ}$ and (d) $\Theta=270^{\circ}$

In more recent studies Okur and Akmandor [7] and Okur and Arabaci [8] also applied a stationary vane rotary expander to realize the Brayton cycle in cost efficient way. Similarly, Zheng et al. [9] applied a rolling piston expander to realize an efficient organic Rankine cycle. Rolling piston expanders can also be applied efficiently for transcritical refrigerator cycles to regain energy from the gaseous refrigerant during the throttling process [10].

Early design of an RPC is introduced by Jaworowski [11] in 1922. Compared to the common RPC architecture (Fig. 1), Jaworowski's compressor applied a swinging vane instead of a sliding vane, and the discharge port was inserted radially and not axially as in most hermetic RPCs in AC units. Essential drawback of the Jaworowski design is that the positioning of the swinging vane is not supported by discharge pressure as in the Yule engine and in most of the common RPCs.

The stationary vane compressor went through significant development since its introduction, which results in various modifications of the base design to achieve better efficiency and improve the applicability of the unit. Beside the beneficial qualities of the baseline architecture, basic RPCs (Fig. 1) have some considerable drawbacks.
To maintain sufficient seal between the compression and suction chamber the vane has to be pressed against the piston surface at relative high force which results in increased overall friction. The friction is also significant on the rest of the sliding surfaces as the result of the high relative velocity difference and the high extension of the sliding surfaces [12].

In order to quantify the potential in RPC design, a brief summary of the published performance data from the literature is presented in Table 1. The different efficiencies are defined by the following correlations:

$$
\begin{aligned}
& \eta_{v}=\frac{\dot{m}_{d}}{n \frac{p_{0}}{R T_{0}} V_{d i s p}} \\
& \eta_{m}=\frac{W_{\text {ind }}}{W_{\text {mot }}} \\
& \eta_{c}=\frac{W_{a d}}{W_{\text {ind }}} \\
& \eta_{c r}=\eta_{v} \eta_{m} \eta_{c}
\end{aligned}
$$

The results in the meaning of volumetric efficiency scatter between $74 \%$ and $98 \%$. In the presented studies the low volumetric efficiencies are the consequences of operating the compressor outside the design conditions. Nevertheless, the expected volumetric efficiency lies above $95 \%$ in case of appropriate design. The determination of mechanical efficiency is not straightforward based on the literature, since the friction losses from the driving

\begin{tabular}{|c|c|c|c|c|}
\hline & 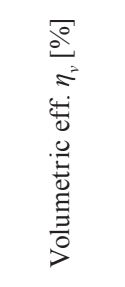 & 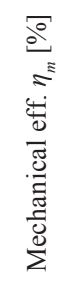 & 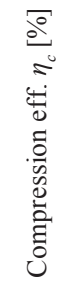 & 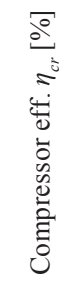 \\
\hline Noh et al. [13] & $75-97$ & & & $55-85$ \\
\hline Park [14] & $74.1-94.3$ & & & \\
\hline Ooi [15] & & 70.95 & & \\
\hline Kim and Bullard [16] & $89-98$ & & & \\
\hline Sakaino et al. [17] & 98.1 & 92 & 86.2 & 52.6 \\
\hline Matsuzaka and Nagatomo [3] & 94 & 93.3 & 94.8 & 72.4 \\
\hline Wakabayashi et al. [18] & & 92.5 & 77.6 & 56 \\
\hline Shiga et al. [19] & 85.7 & & & \\
\hline
\end{tabular}
unit and the standalone compressor cannot be unambiguously differentiated.

Table 1 Expected Rolling Piston compressor performance data 
The $71 \%$ mechanical efficiency presented by Ooi [15] is probably more feasible prediction compared to efficiencies above $90 \%$. The values of presented compression efficiencies also vary significantly between 78 and $95 \%$. However, all the presented compression efficiency estimations are claimed to be based on experimental data with the use of R22 refrigerant.

The indicated pressure diagram (Fig. 3) represents the indicated work, hence it also indicates the hydraulic and heat transfer related losses during the compression process. The additional work to the isentropic process consist the following losses:

- Wiredrawing loss is the work which is employed to drag the working fluid to the suction chamber from the ambient. Its value is proportional to the area of the indicator diagram which is below $p_{0}$.

- Over-compression loss is the result of the excessive pressure required to overcome the resistance of the discharge port and valve to trust the working fluid into the following high pressure $\left(p_{d}\right)$ chamber. This work appears in the indicator diagram as the area above the discharge pressure $p_{d}$.

- Reexpansion loss arose by the pressurized working fluid in the clearance volume which reexpands into the suction chamber. The reexpansion loss is proportional to the area bounded by sections connecting the points $2 \mathrm{~s}-2-3$ '-3s in Fig. 3.

- Leakage loss depending on the construction part of the compressed working fluid leaves the compression chamber across the sealing clearances imposing compression and heating loss. In case of hermetic compressors, the working fluid can also reenter to the compression and suction chambers since the compressor is mounted into the high pressure vessel. The leakage into the suction chamber decreases the volumetric efficiency.

- Heating loss is the result of the heat transfer across the compressor shell and also the heat transferred by the leakage flow. This loss result in deviation from the adiabatic process represented by adiabatic connecting the points $2-3^{\prime}$ to the real process represented by the section of the indicator diagram between the points 2 and 3 .

To reach the expected compressor performance, RPCs use additional lubrication which both keeps the surface friction below a proper limit and seals the gaps within the cylinder, thus prevent excessive leakage through

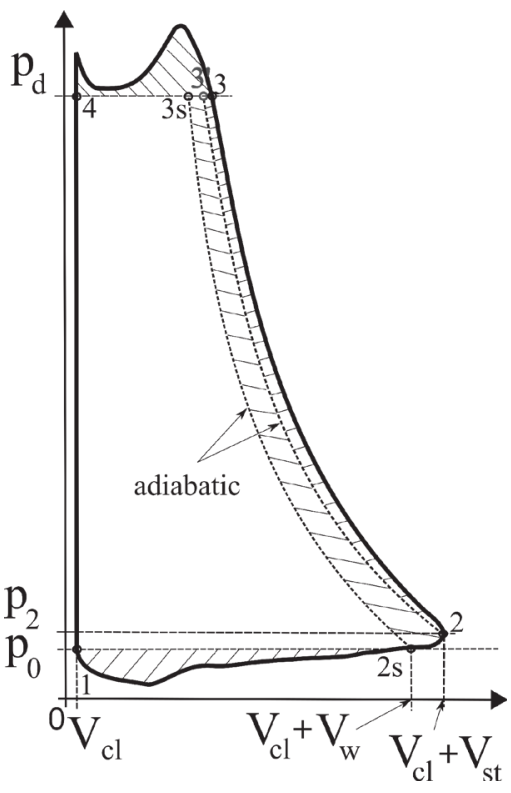

Fig. 3 Illustration of a typical RPC indication diagram [18]

the seal clearances. The lubrication requires an appropriate lubrication system therefore increases the complexity of the system and also utilizes part of the shaft work input to maintain proper lubricating oil recalculation. In case of AC systems, the lubricant degrades the quality refrigerant, i.e. the reduction or elimination of the necessary amount of lubricant within the displacement volume is desirable. Also, some particular applications require the elimination of any oil contamination. In case of environmental requirements neutral lubricant can be considered as possible alternative lubricant. Delmotte [20] applied water lubrication for a shipboard, multistage, high pressure air RPC system in addition to the use of non-metallic bearings and injecting water directly into the suction chamber at the compressor inlet.

The conventional RPC architecture has to be modified in order to accomplish efficient compressor operation in case of the complete absence of fluid lubricant within the compression chamber. Stoltz [21] developed a swinging bush (SB) type stationary vane design for vacuum tube manufacturing, where oil contamination is inadmissible. Very similar architecture along with the hinged vane HV design [7] was proposed by Wu and Chen [22] for oil free operation in AC RCP's. In case of SB and HV designs friction force and the relative velocity between the connecting parts are reduced e.g. less or no liquid lubricant needed and still maintaining stable operation. The applied vane mounts in SB and HV compressors also reduce significantly the leakage flow. 


\section{The new compressor design}

The RPC based architecture (Fig. 4) introduced by Farkas et al. [23] is also designed to minimalize leakage flow in oil-free operation.

In this design the vane is positioned by a pivoted beam similarly to the construction introduced by Jaworowski [11]. However, in this case the vane is actuated by a linkage mechanism which is directly driven by the crankshaft to keep constant clearance between the vane and the piston [24]. During the test period the initial prototype geometry was modified to improve the reliability and decrease the wiredrawing loss. The solid pivoted supporting beam (Fig. 4) was replaced first by a hollow support beam (HB) (Fig. 5) and finally by a narrower and lighter support beam (NB) (Fig. 6). Fig. 7 presents the vane actuating mechanism at the upper dead center position.

The modified construction resulted in lowered wiredrawing loss by the modified intake. It also increased the volumetric efficiency by reducing the tangential extension of the inlet slot downstream the vane support. The mechanical efficiency is expected to be enhanced by the lighter weight of the vane support beam. The modifications result eventually also in cleaner and simpler design from manufacturing point of view. The inlet and outlet are radial because of installation requirements.

\section{Accessing performance by CFD}

Performance evaluation of the novel compressor was performed based on Computational Fluid Dynamics (CFD) simulation results. The use of CFD tools has become a common practice even in case of volumetric machines.

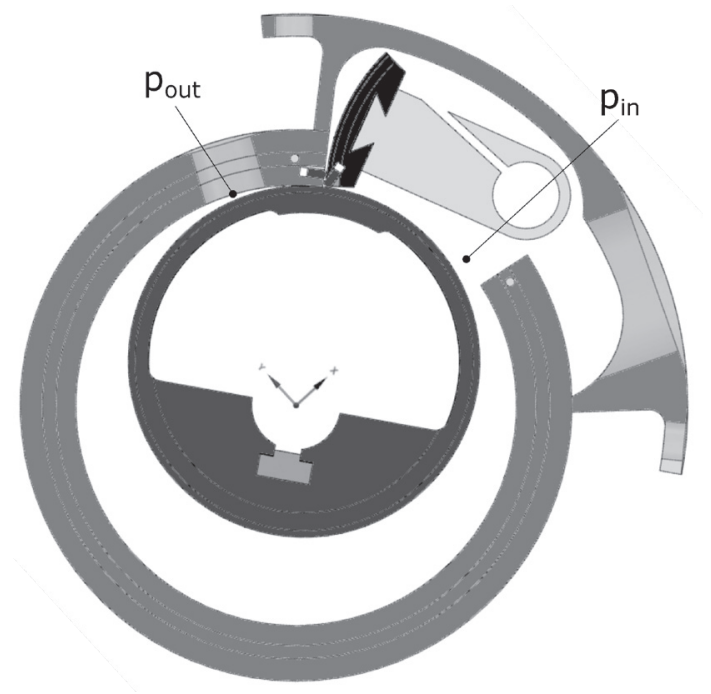

Fig. 4 Initial prototype geometry. $p_{\text {in }}$ and $p_{\text {out }}$ marking the locations from where the pressures for the indicator diagrams were extracted

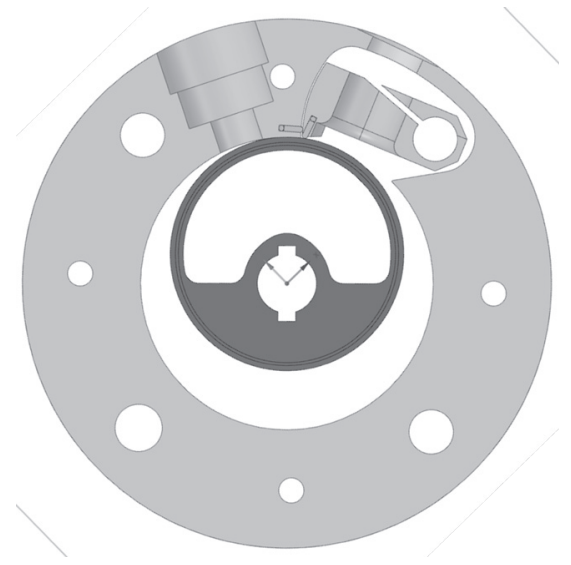

(a)

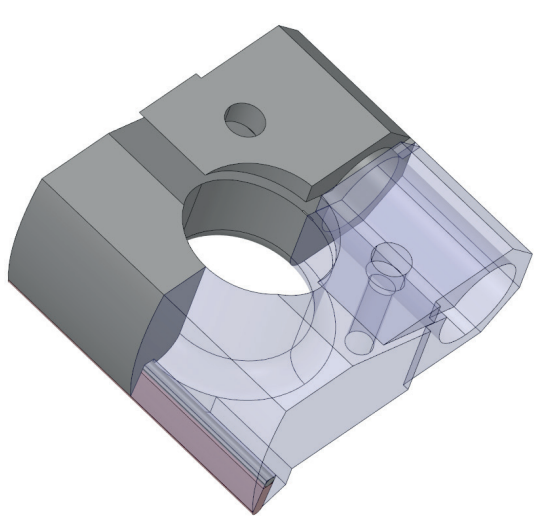

(b)

Fig. 5 Schematic of the compressor with hollow beam vane support (a) and the 3D modell of the applied hollow beam / vane system (HB) (b)

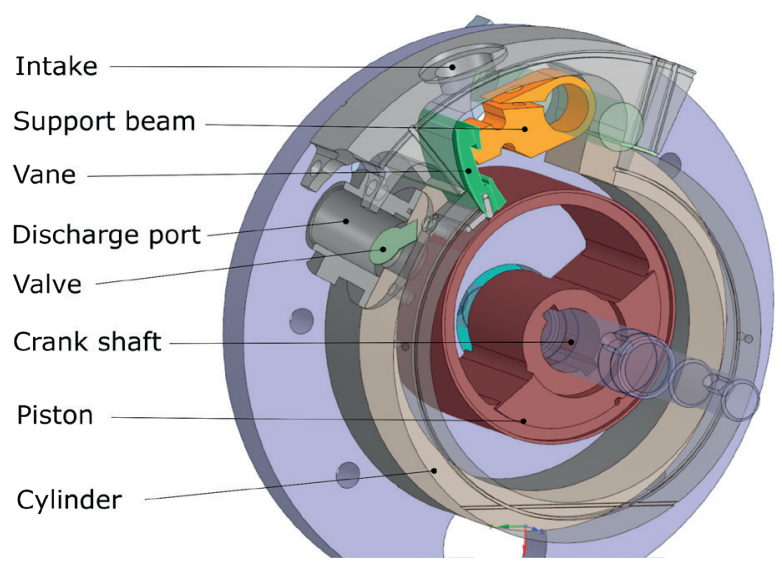

Fig. 6 Schematic of the final geometry with narrow support beam (NB)

CFD models are used both to access performance data for design prior the experiments and evaluating the measured data and also for parametric studies.

There are CFD solver packages which are directly designed to evaluate common compressor and turbine designs, e.g. PumpLinx [25, 26]. Other commercially 


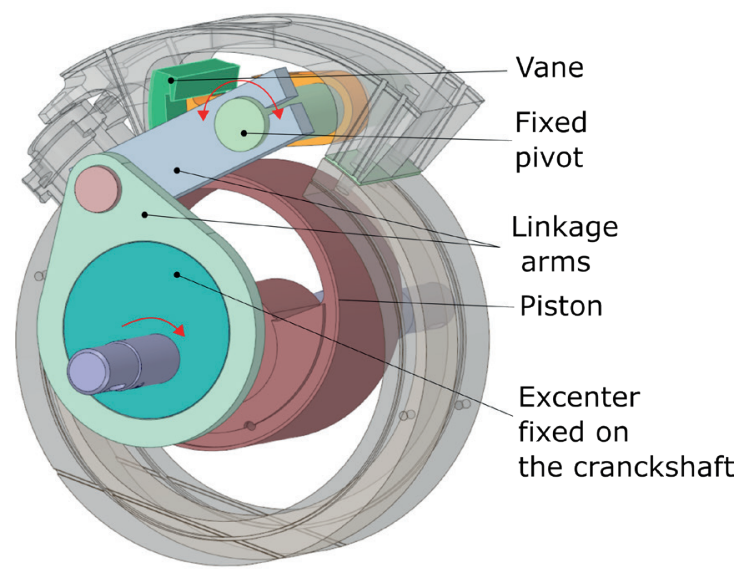

Fig. 7 Vane actuating linkage mechanism

available and open source CFD solvers with dynamic mesh options can be also applied to simulate volumetric machine operation, e.g. Star-CD [27-29], Ansys CFX [30], Ansys Fluent [23, 31], etc. Meanwhile the specially targeted programs allows easy setup and faster evaluation, the universal CFD programs are more versatile i.e. can model architectures which differs from the conventional compressor designs.

\subsection{Description of the model}

\subsubsection{Computational domain}

The geometry and the numerical mesh was created within the framework of Ansys Workbench using Design Modeler for the geometry model (Fig. 8) and Ansys Meshing for discretizing the computational domain (Fig. 9).

Since the boundary conditions are symmetrical to the transversal mid-plane of the compressor geometry, only half of the domain was meshed. Within computational domain, the parts which are swept by the motion of the piston and the vane are discretized by triangular prism elements. Some sections of the domain, which are not affected by the moving parts are meshed by hex dominant prism elements using multizone or sweep method in order to decrease the required computational resources. The connection of the cylinder to the inlet and the discharge port are non-conform, i.e. the mesh sections are connected via non-matching interfaces.

The mesh of the discharge port incorporates the discharge valve. The areas which are swept by the moving valve are meshed with hex dominant prismatic elements to allow the application of the layering dynamic meshing method which is discussed in detail in Section 3.1.2.

Eventually the initial mesh count result in approximately $1.5 \times 10^{5}$ elements in total.

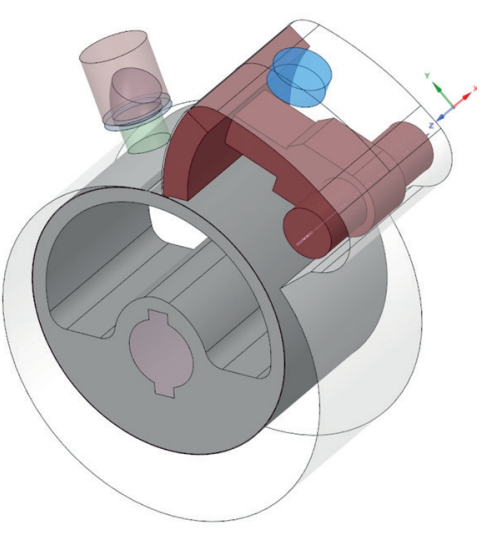

Fig. 8 3D schematic of the computational domain of the final geometry with NB

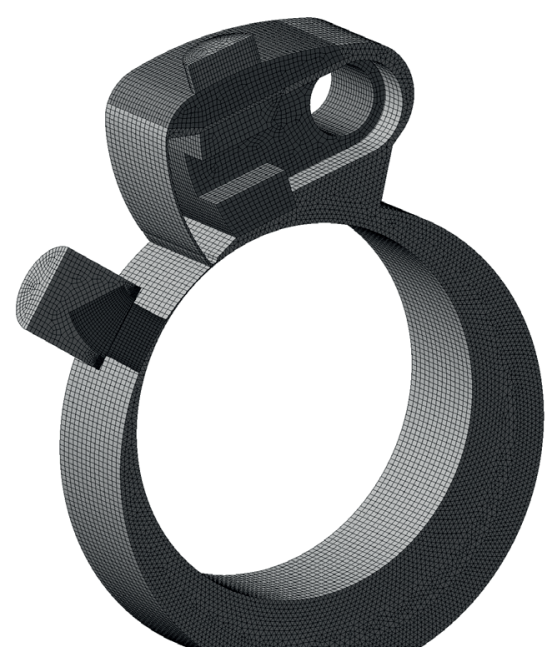

Fig. 9 Mesh of the computational domain, including only prismatic elements within the dynamic mesh domain

\subsubsection{Dynamic mesh}

During the rotation of the piston the volume of the suction chamber increases meanwhile the compression chamber volume decreases. Because of the change in volume and shape of the computational domain, the mesh has to be also adapted accordingly. In case of conventional design, it is enough to deform the mesh while the shape of the computational domain changes without changing the number of mesh elements as it is published in most of the studies in the related literature, e.g. [23, 25, 27-29]. However, in the recent case the interaction of the swinging vane mechanism and the piston result in complex change of the geometry which cannot be followed by straight forward deforming mesh algorithms. In this case deforming and remeshing methods have to be used in together. Namely, when the quality of the deforming mesh degrades below a predefined limit the critical elements are marked and remeshed during the initialization of the next model 
time step. In the presented cases face skewness was chosen to be limited to maximum 0.9 . The remeshing occurred at every $5^{\text {th }}$ time step if marked cells beyond the given limit were present within the dynamic domain. The maximum length scale was limited to $1 / 20^{\text {th }}$ of the piston radius.

To combine the advantages of the above described methods a hybrid mesh was set up. The stroke volume was divided into two distinct parts, as shown in Fig. 10. The connections between these two parts are conformal. The change of geometry and node distribution on the interface between the parts has to be defined explicitly by the user via a user defined function (UDF). As Fig. 10 also shows, the dynamic mesh works if serial process is used, but at the moment it cannot be parallelized in Fluent. The use of Fluent inbuilt remeshing algorithm alongside with the UDF which defines the position of the nodes at the connecting region results in interference with the Fluent Message Passing Interface (MPI). Although, the hybrid dynamic meshing method allows better control on mesh quality and better resolution at lower cell count, this method was currently dismissed and full remeshing method was used instead.

The dynamic mesh parts within the cylinder (Fig. 9 and Fig. 10) are controlled by Fluent 2.5D remeshing method, i.e. only one side face of the cylinder is re-meshed and the resulted mesh is inherited to the parallel layers after.

The motion of the discharge valve was modelled by the use of the layering dynamic meshing method. In case of the NB design the motion of the valve is defined along a torus (Fig. 11). The valve in the prototype is hinged and its practical motion at low openings is considered to be in acceptable resemblance to the valve trajectory in the NB prototype compressor (Fig. 6).

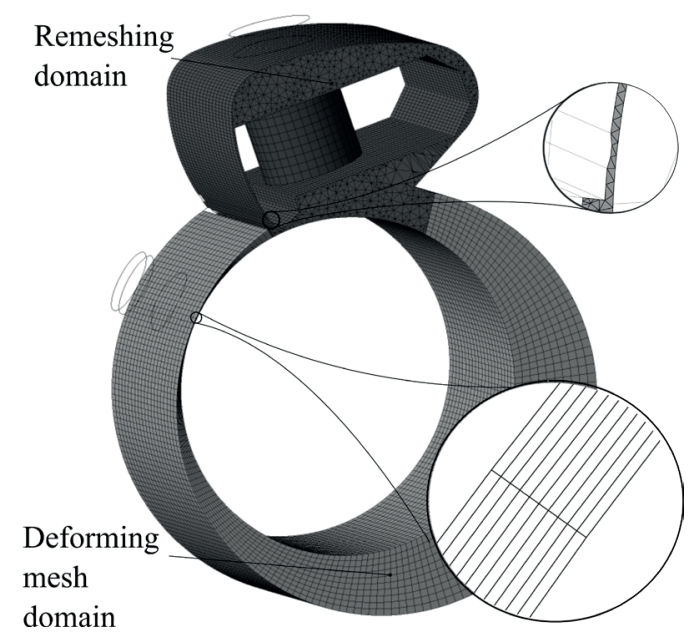

Fig. 10 Hybrid mesh for hollow beam design
During the initial test period the above discussed hinged discharge valve had not been accessible, therefore a commercially available, spring loaded, pneumatic check valve was planned to be used for the early experimental runs. Hence the HB compressor models are implemented with the numerical model of the check valve which is presented is presented in Fig. 12.

In case of the layering dynamic meshing method the neighboring layer to the valve surface is segmented or united to the following layers to keep the mesh resolution within predefined limits. In this case the point when the layer collapsed or segmented were given in height ratios.

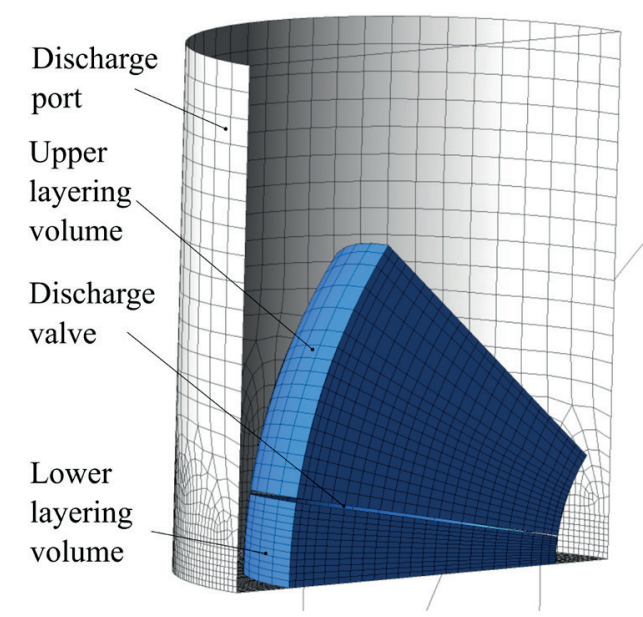

Fig. 11 3D representation of the numerical mesh of the discharge valve for the final NB design

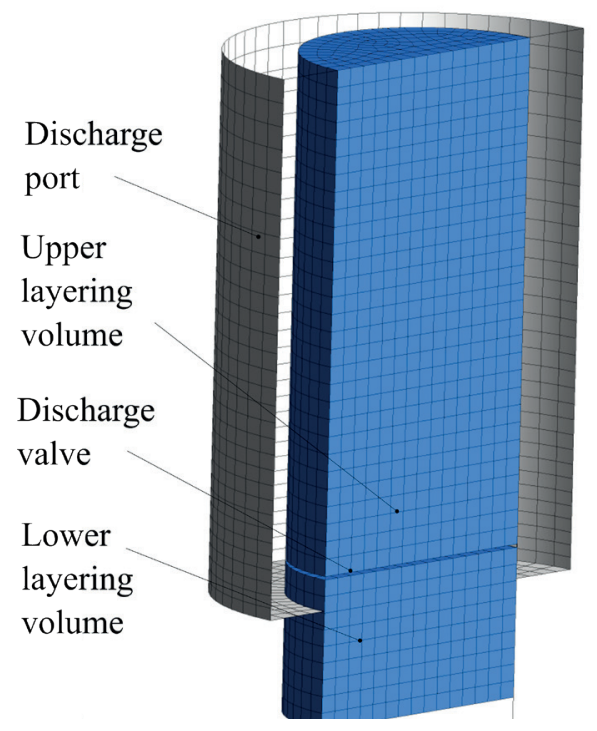

Fig. 12 Crossection of the numerical mesh of the straight discharge valve aplied for cmopressor with $\mathrm{HB}$ 
Table 2 Main dimensions of the compressor unit

\begin{tabular}{lc}
\hline Part name & Dimension $[\mathrm{mm}]$ \\
\hline Cylinder radius & 50 \\
Cylinder width & 40 \\
Eccentricity & 10 \\
Piston radius & 40 \\
Design sealing gap clearance size & $<0.001$ \\
\hline
\end{tabular}

\subsubsection{Modelling the leakage flow across the sealing clearances}

To model the sealing clearance flow, the clearance channels have to be discretized at adequate resolution. Since the clearance channel height is several magnitudes lower than the overall dimensions of the numerical domain (Table 2), this resolution would result in mesh size which is beyond manageable magnitude in case of the selected remeshing method (Fig. 9).

Hence, the clearance channels were meshed by low resolution mesh which allows only one mesh element along the channel height as presented in Fig. 10 within the remeshing domain.

The restrictions by the friction imposed by the walls of the narrow channels are modelled by the addition of a momentum source term which models the effect of porous media.

The method was described in details by Farkas et al. [30] and Camp Sud [31]. To model the restriction, Darcy's law (Eq. (5)) was applied assuming that across the narrow channel the leakage flow remains laminar.

$\nabla p=-\frac{\mu}{\alpha} \bar{v}$

By adjusting the $\alpha$ permeability in Eq. (5) at constant $\mu$ viscosity, the desired restriction can be set. By imposing the porous term, the channel height does not have to match the exact value from the real geometry, e.g. the channel height can be increased keeping the imposed restriction at the same level by increasing the porous term. Since the channel height defines the mesh size, the mesh size can be also increased with the increase of the channel height which results in lower computational cost. At the current case the highest possible porous resistance was modelled to simulate enhanced sealing e.g. best possible compressor performance. For the presented simulations the viscous resistance $(1 / \alpha)$ was set to 1 e12. At this level of $1 / \alpha$ stable simulations could be performed which are representative for microscopic clearances. In possession of sufficient measurement data, the viscous resistance can be further adjusted. In case it is necessary, the porous source term can be completed with the inertial loss term.

\subsubsection{Solver}

For the simulations the double precision density based Fluent solver was selected as the expected change in density is significant and the description of the timely position of the moving parts requested enhanced precision.

The turbulence behavior was resolved by $k-\varepsilon$ turbulence model. For spatial discretization second order upwind methods were applied along with computing the gradients by least square cell-based method. Because of the moving mesh first order implicit transient formulation was applied.

The boundary condition at the inlet $\left(p_{0}\right)$ and outlet $\left(p_{d}\right)$ were set to constant pressure. Because only one half of the compressor was modelled symmetry boundary condition was applied at the location of the symmetry plane. All the bounding surfaces were set to be adiabatic, e.g. at this stage no heat transfer was modelled.

The simulation for one revolution took approximately 72 hours on a quad-core $17 \mathrm{k} 2600$ processor when the mesh counted $1.5 \times 105$ cells in average. The simulations were run on parallel solver distributing the workload among the four cores available in one processor.

\subsection{Results}

First the model of the HB construction (Fig. 5) was evaluated. There is a significant change in indicated diagrams as the pressure ratio $\left(p / p_{0}\right)$ and rotational speed was changed (Fig. 13). At low rotational speed the working fluid has more time to leave the compression chamber trough the clearances. As the rotational speed increases the compression section gets steeper and at certain points starts to drop again. Same variation in volumetric efficiencies can be followed in Table 1. It implicates that increasing speed the amount of leakage flow drops but also the amount of ingested working fluid drops as well which result in an optimum.

The final NB design (Fig. 6) was evaluated at different pressure ratios at $1200 \mathrm{rpm}$ crankshaft speed (Fig. 14).

Meanwhile the gradient of pressurize section remains constant, the volumetric efficiency drops significantly (Table 3). This also justifies that the gradient of the pressurize in this case depends only from the rotational speed. Since the clearance volumes remain the same, the re-expansion loss becomes higher as the backpressure increases, however, it does not modify the steepness of the curves. 


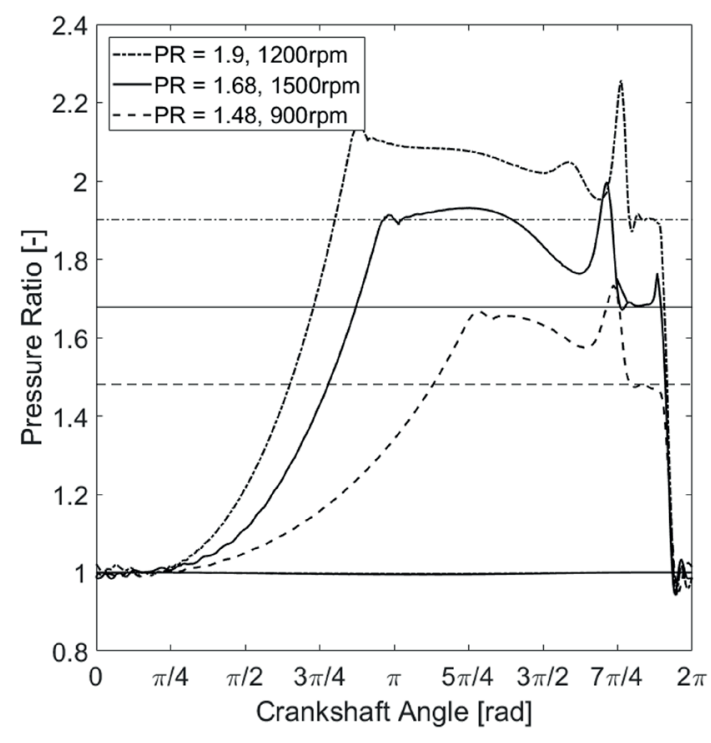

Fig. 13 Indicated pressure diagrams with HB

Table 3 Volumetric efficiencies

\begin{tabular}{lccc}
\hline Beam construction type & $\begin{array}{c}\text { Rotational } \\
\text { speed, } \\
n[\mathrm{rpm}]\end{array}$ & $\begin{array}{c}\text { Pressure } \\
\text { ratio, } \\
\text { PR [-] }\end{array}$ & $\begin{array}{c}\text { Volumetric } \\
\text { efficiency, } \\
\eta_{v}[\%]\end{array}$ \\
\hline \multirow{3}{*}{ Hollow Beam (HB) } & 900 & 1.48 & 35 \\
& 1200 & 1.90 & 87 \\
Narrow Beam (NB) & 1500 & 1.68 & 72 \\
& & 1.50 & 88 \\
& & 1.70 & 86 \\
\hline
\end{tabular}

The discharge valve is pressure activated. The instantaneous rotational speed of the valve along its hinge can be calculated as presented in Eq. (6).

$\omega_{v+d t}=\omega_{v}+\frac{M_{p}-\beta \cdot k-M_{p r e}}{I_{v}} d t$

Where $\omega_{v}$ is the rotational speed at the current time step, $d t$ is the size of the computational time step, $M_{p}$ is the momentum form the pressure difference, $\beta$ is the current opening angle of the valve, $M_{c}$ is the momentum from the spring stiffness, $M_{p r e}$ is the momentum from the valve preload and $I_{v}$ is the moment of inertia of the vane.

In case of the check valve Fig. 12 which was used in the HB compressor the movement is translational therefore the state of motion can be defined by Eq. (7).

$v_{v+d t}=v_{v}+\frac{F_{p}-x \cdot K-F_{p r e}}{m_{v}} d t$

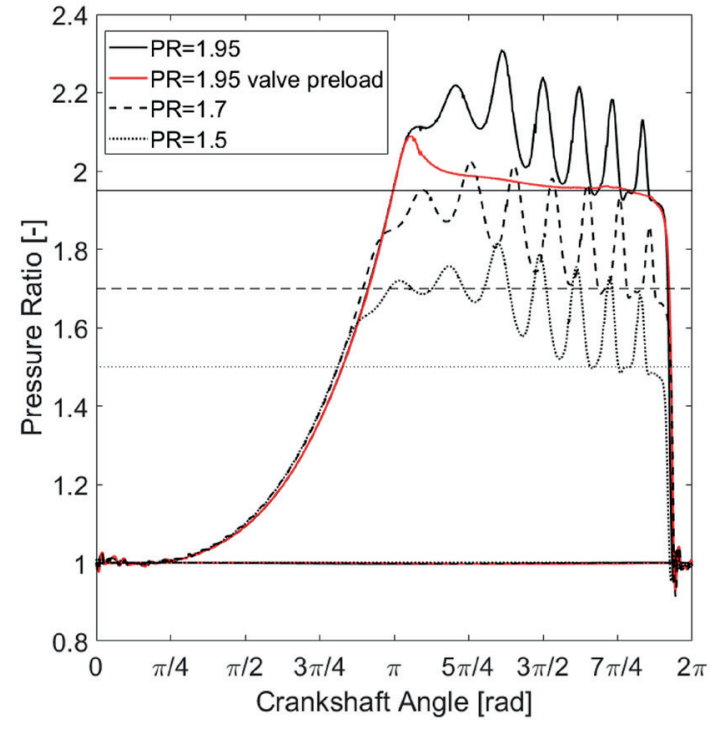

Fig. 14 Effect of pressure ratio and valve pre-load on the indicator diagram

Where $v_{v}$ is the velocity at the given time step, $F_{p}$ is force acting on the valve resulted from the pressure difference on the valve surfaces $K$ is the spring stiffness, $x$ is valve opening $F_{p r e}$ is the preload of the valve spring, and $m_{v}$ is the weight of the valve.

When low preload at the vane spring was modelled, significant fluctuation occurred during discharge in compression chamber pressure (Fig. 14). This fluctuation appears to be similar to the indicated pressure diagrams presented by Teh and Ooi [32] in case of their Rotating Vane (RV) related experiments. Although, it was not stated explicitly, the fluctuation of the pressure in case of RV compressors can be the result of the additional centrifugal force on the discharge valve. In case of their RV compressor architecture [32], the discharge valve is attached to the cylinder which is not stationary but rotated in the speed of the crankshaft. Hence, the preload and spring stiffness is reduced by the effect of the centrifugal force.

By the increase of preload and limiting the maximal valve opening, the fluctuation diminished. Negligible change in volumetric efficiency has been also appeared with the additional change in valve parameters. The $1 \%$ drop from $81 \%$ to $80 \%$ (Table 3 ) is not significant and lies within the estimated CFD modelling accuracy.

The difference in modelling the discharge valves (Fig. 9, Fig. 11 and 12) result in higher overshoot in case of the HB design. Also the course of the pressure curves during the discharge are significantly different which also resulted by the different dynamical properties of the simulated valves. Important feature of the layering method can 
also be observed in Fig. 14. Small spikes appear on the curve which represents the case with $\mathrm{PR}=1.95$ when no preload on the valve spring was imposed. These spikes are the results of the collapsing or splitting of the cells which form the layering region.

The difference in the predicted volumetric efficiency between the two constructions (Table 3) is more pronounced. The drop in efficiency in case of the final design is partly resulted by the increased in size of intake slot. In Fig. 6 it can be observed that the solid cylinder was replaced by a thinner casing and the additional lip in case of the HB design (Fig. 5) was removed in the sake of cost efficient manufacturing.

The suction chamber pressure was taken at the inlet of the compression chamber downstream from the vane mechanism ( $p_{i n}$ in Fig. 4). It can be seen on both indicated pressure diagrams Fig. 13 and Fig. 14 that the wiredrawing loss is close to negligible at these low rotational speeds as the result of the large intake cross-sections.

\section{Summary}

Important aspects of evaluating an RP design based rotary compressor based on CFD data was presented in the recent manuscript. The calculated results were compared to the available data from literature. The estimated performance of the new design slightly fells off from the conventional RP design because of the oil free architecture. It was found that the enlarged extend of the intake slot and the radial outlet which is further upstream from the vane decreases the volumetric efficiency. However, because of mechanical and construction restrictions the position of the radial outlet is fixed. The increased distance of the discharge port from the vane increases the clearance loss which significantly increases the re-expansion loss which appears in degradation of volumetric efficiency as the pressure ratio increases. The wiredraw loss was lowered, which is the result of the low rotation speed and the enlarged intake port.

The results are in reasonable resemblance with the data presented in literature. It is presented that the established CFD model can provide useful data to support the development of the new oil-free compressor design.

\section{Acknowledgement}

The research project reported in this paper has been supported by the Higher Education Excellence Program of the Ministry of Human Capacities in the frame of Artificial Intelligence Research area of Budapest University of Technology and Economics (BME FIKP-MI Future Mobility).

$\begin{array}{cl}\text { Abbreviations } \\ \text { CFD } & \text { Computational Fluid Dynamics } \\ \text { HB } & \text { Hollow Beam } \\ \text { HV } & \text { Hinged Vane } \\ \text { MPI } & \text { Message Passing Interface } \\ \text { NB } & \text { Narrow Beam } \\ \text { SB } & \text { Swing Bush } \\ \text { UDF } & \text { User Defined Function }\end{array}$

\section{Nomenclature}

\begin{tabular}{|c|c|}
\hline$d t$ & simulation time step (s) \\
\hline$I$ & moment of inertia $\left(\mathrm{kg} \cdot \mathrm{m}^{2}\right)$ \\
\hline K & spring stiffness $\left(\mathrm{N} \cdot \mathrm{m}^{-1}\right)$ \\
\hline$k$ & rotational spring stiffness $\left(\mathrm{N} \cdot \mathrm{rad}^{-1}\right)$ \\
\hline$M$ & momentum $(\mathrm{N} \cdot \mathrm{m})$ \\
\hline$m$ & $\operatorname{mass}(\mathrm{kg})$ \\
\hline$\dot{m}$ & mass-flow rate $\left(\mathrm{kg} \cdot \mathrm{s}^{-1}\right)$ \\
\hline$n$ & rotational speed $\left(\mathrm{s}^{-1}\right)$ \\
\hline$p$ & pressure $(\mathrm{Pa})$ \\
\hline$R$ & specific gas constant $\left(\mathrm{J} \cdot \mathrm{kg}^{-1} \cdot \mathrm{K}^{-1}\right)$ \\
\hline$T$ & temperature $(\mathrm{K})$ \\
\hline$V$ & volume $\left(\mathrm{m}^{3}\right)$ \\
\hline$W$ & work $(\mathrm{J})$ \\
\hline \multicolumn{2}{|l|}{ reek } \\
\hline$\alpha$ & permeability $\left(\mathrm{m}^{2}\right)$ \\
\hline$\beta$ & valve opening angle (rad) \\
\hline$\eta$ & efficiency $(\%)$ \\
\hline$\Theta$ & crankshaft angle (deg) \\
\hline$\mu$ & viscosity $(\mathrm{Pa} \cdot \mathrm{s})$ \\
\hline$\omega$ & Rotational speed $\left(\mathrm{s}^{-1}\right)$ \\
\hline \multicolumn{2}{|c|}{ ubscript } \\
\hline ad & adiabatic \\
\hline$c$ & compression \\
\hline $\mathrm{cr}$ & compressor \\
\hline ind & indicated \\
\hline$m$ & mechanical \\
\hline mot & motor \\
\hline$v$ & valve \\
\hline 0 & inlet boundary condition \\
\hline in & suction pressure \\
\hline out & compression pressure \\
\hline$d$ & discharge pressure \\
\hline Iiscell & \\
\hline$\nabla$ & gradient \\
\hline
\end{tabular}




\section{References}

[1] ASHRAE "Chapter 37, Compressors", In: 2008 ASHRAE Handbook: HVAC Systems and Equipment, ASHRAE American Society of Heating, Refrigerating and Air-Conditioning Engineers, Atlanta, USA, 2008, pp. 37.1-37.38.

[2] Ma, Y., Zhang, B., Hwang, Y. H., Peng, X. Y., Xing, Z. W. "Research and development of a semi-hermetic reciprocating compressor for transcritical $\mathrm{CO}_{2}$ refrigeration cycle", Proceedings of the Institution of Mechanical Engineers, Part A: Journal of Power and Energy, 225(1), pp. 101-113, 2011. https://oi.org/10.1177/09576509JPE1070

[3] Matsuzaka, T., Nagatomo, S. "Rolling Piston Type Rotary Compressor Performance Analysis", In: International Compressor Engineering Conference, West Lafayette, Indiana, USA, 1982, pp. 149-158. [online] Available at: https://docs.lib.purdue.edu/ icec/386/ [Accessed: 28 May 2019]

[4] Yang, H., Qu, Z., Zhou, H., Yu, B. "Study on leakage via the radial clearance in a novel synchronal rotary refrigeration compressor", International Journal of Refrigeration, 34(1), pp. 84-93, 2011. https://doi.org/10.1016/j.ijrefrig.2010.08.007

[5] Gasche, J. L., Andreotti, T., Maia, C. R. M. "A model to predict $\mathrm{R} 134 \mathrm{a}$ refrigerant leakage through the radial clearance of rolling piston compressors", International Journal of Refrigeration, 35(8), pp. 2223-2232, 2012. https://doi.org/10.1016/j.ijrefrig.2012.07.015

[6] Bourne, J. "A Treatise on the Steam Engine in Its Application to Mines, Mills, Steam Navigation, and Railways", Longman, Brown, Green, and Longmans, London, UK, 1847.

[7] Okur, M., Akmandor, I. S. "Experimental investigation of hinged and spring loaded rolling piston compressors pertaining to a turbo rotary engine", Applied Thermal Engineering, 31(6-7), pp. 1031-1038, 2011.

https://doi.org/10.1016/j.applthermaleng.2010.11.027

[8] Okur, M., Arabaci, E. "Experimental study of a novel hinged vane rotary turbine - part I: The effect of different vane thickness and vane weight on turbine performance", International Journal of Refrigeration, 51, pp. 70-76, 2015.

https://doi.org/10.1016/j.ijrefrig.2014.12.012

[9] Zheng, N., Zhao, L., Wang, X. D., Tan, Y. T. "Experimental verification of a rolling-piston expander that applied for low-temperature Organic Rankine Cycle", Applied Energy, 112, pp. 1265-1274, 2013. https://doi.org/10.1016/j.apenergy.2012.12.030

[10] Jiang, Y., Ma, Y., Fu, L., Li, M. "Some design features of $\mathrm{CO}_{2}$ two-rolling piston expander", Energy, 55, pp. 916-924, 2013. https://doi.org/10.1016/j.energy.2013.03.053

[11] Jaworowski, J. F. "Air Pump", Cleveland, Ohio, United States of America, US 1,677,780A, 1928.

[12] Ooi, K. T., Yap, K. S. "Design Evolution: From Rolling Piston to Revolving Vane to Cross-Vane Expander-compressor unit", IOP Conference Series: Materials Science and Engineering, 90, article ID: 012036, 2015.

https://doi.org/10.1088/1757-899X/90/1/012036
[13] Noh, K.-Y., Min, B.-C., Song, S.-J., Yang, J.-S., Choi, G.-M., Kim, D.-J. "Compressor efficiency with cylinder slenderness ratio of rotary compressor at various compression ratios", International Journal of Refrigeration, 70, pp. 42-56, 2016. https://doi.org/10.1016/j.ijrefrig.2016.06.020

[14] Park, Y. C. "Transient analysis of a variable speed rotary compressor", Energy Conversion and Management, 51(2), pp. 277-287, 2010. https://doi.org/10.1016/j.enconman.2009.09.023

[15] Ooi, K. T. "Design optimization of a rolling piston compressor for refrigerators", Applied Thermal Engineering, 25(5-6), pp. 813-829, 2005.

https://doi.org/10.1016/j.applthermaleng.2004.07.017

[16] Kim, M. H., Bullard, C. W. "A Simple Approach to Performance Analysis of Alternative Refrigerant Rolling-Piston-Type Rotary Compressors", Air Conditioning and Refrigeration Center, Mechanical \& Industrial Engineering Dept., University of Illinois, Urbana, IL, USA, Rep. ACRC CR-34, 2001. [online] Available at: http://hdl.handle.net/2142/13358 [Accessed: 15 February 2019]

[17] Sakaino, K., Muramatsu, S., Shida, S., Ohinata, O. "Some Approaches Towards a High Efficient Rotary Compressor", In: International Compressor Engineering Conference, West Lafayette, Indiana, USA, 1984, pp. 315-322. [online] Available at: http://docs.lib.purdue.edu/icec/469 [Accessed: 28 May 2019]

[18] Wakabayashi, H., Yuuda, J., Aizawa, T., Yamamura, M. "Analysis of Performance in a Rotary Compressor", In: International Compressor Engineering Conference, West Lafayette, Indiana, USA, 1982, pp. 140-147. [online] Available at: http://docs.lib.purdue.edu/icec/385 [Accessed: 15 February 2019]

[19] Shiga, T., Ishijima, K., Sakainc, M., Chu, I. "Analysis of The Rolling-Piston Type Rotary Compressor", In: International Compressor Engineering Conference, West Lafayette, Indiana, USA, 1978, pp. 219-225. [online] Available at: http://docs.lib.purdue.edu/icec/269 [Accessed: 15 February 2019]

[20] Delmotte, S. J. "Development of a High Pressure, Oil Free, Rolling Piston Compressor", In: International Compressor Engineering Conference, West Lafayette, Indiana, USA, 1994, pp. 543-548. [online] Available at: https://docs.lib.purdue.edu/icec/1033 [Accessed: 15 February 2019]

[21] Stoltz, H. I., Kinney Manufacturing Company "High Vacuum Pump Apparatus", Hyde Park, Massachusetts, USA, US 2,215,256A, 1940.

[22] Wu, J. H., Chen, A. "A new structure and theoretical analysis on leakage and performance of an oil-free R290 rolling piston compressor", International Journal of Refrigeration, 49, pp. 110-118, 2015. https://doi.org/10.1016/j.ijrefrig.2014.10.007

[23] Farkas, B., Szente, V., Suda, J. M. "Dynamic meshing strategies to model fluid flow in rolling piston compressors", In: The $16^{\text {th }}$ International Conference on Fluid Flow Technologies, Conference on Modelling Fluid Flow (CMFF'15), Budapest, Hungary, 2015, paper ID: 135. [online] Available at: http://real.mtak.hu/id/ eprint/26064 [Accessed: 15 February 2019] 
[24] Farkas, B., Suda, J. M. "Performance analysis of a novel oil-free rotary compressor", Proceedings of the Institution of Mechanical Engineers, Part A: Journal of Power and Energy, 232(7), pp. 870-887, 2018. https://doi.org/10.1177/0957650918757876

[25] Ding, H., Gao, H. "3-D Transient CFD Model For A Rolling Piston Compressor With A Dynamic Reed Valve", In: $22^{\text {nd }}$ International Compressor Engineering Conference, West Lafayette, Indiana, USA, 2014, paper ID: 1548. [online] Available at: http://docs.lib. purdue.edu/icec/2362/ [Accessed: 15 February 2019]

[26] Geng, W., Liu, C. H., Wang, Y. Z. "The Performance Optimization of Rolling Piston Compressors Based on CFD Simulation", In: International Compressor Engineering Conference, West Lafayette, Indiana, USA, 2004, paper ID: C013. [online] Available at: http://docs.lib.purdue.edu/icec/1621 [Accessed: 15 February 2019]

[27] Liu, C. H., Geng, W. "Reserach on Suction Performance of TwoCylinder Rolling Piston Type Rotary Compressors Based on CFD Simulation", In: International Compressor Engineering Conference, West Lafayette, Indiana, USA, 2004, paper ID: C101. [online] Available at: http://docs.lib.purdue.edu/icec/1619 [Accessed: 15 February 2019]

[28] Liang, S., Xia, S., Kang, X., Zhou, P., Liu, Q., Hu, Y. "Investigation of Refrigerant Flow Simulation and Experiment of Rolling Piston", In: International Compressor Engineering Conference, West Lafayette, Indiana, USA, 2010, paper ID: 1164. [online] Available at: http://docs.lib.purdue.edu/icec/1955 [Accessed: 15 February 2019]
[29] Ba, D.-C., Deng, W.-J., Che, S.-G., Li, Y., Guo, H.-X., Li, N., Yue, X.-J. "Gas dynamics analysis of a rotary compressor based on CFD", Applied Thermal Engineering, 99, pp. 1263-1269, 2016. https://doi.org/10.1016/j.applthermaleng.2016.01.062

[30] Farkas, B., Szente, V., Suda, J. M. "A Simplified Modeling Approach for Rolling Piston Compressors", Periodica Polytechnica Mechanical Engineering, 59(2), pp. 94-101, 2015. https://doi.org/10.3311/PPme.7936

[31] Campo Sud, D. D. "Analysis of the Suction Chamber of External Gear Pumps and their Influence on Cavitation and Volumetric Efficiency", Doctoral Thesis, Universitat Politècnica de Catalunya (UPC), Laboratorio de Sistemas Oleohidráulicos y Neumáticos (LABSON), Barcelona, Spain, 2012. [online] Available at: https://upcommons.upc.edu/handle/2117/94595 [Accessed: 15 February 2019]

[32] Teh, Y. L., Ooi, K. T. "Experimental study of the Revolving Vane (RV) compressor", Applied Thermal Engineering, 29(14-15), pp. 3235-3245, 2009.

https://doi.org/10.1016/j.applthermaleng.2009.04.029 